\title{
In memoriam Profesor Dr. Edgardo Carrasco Calderón (1928-2015)*
}

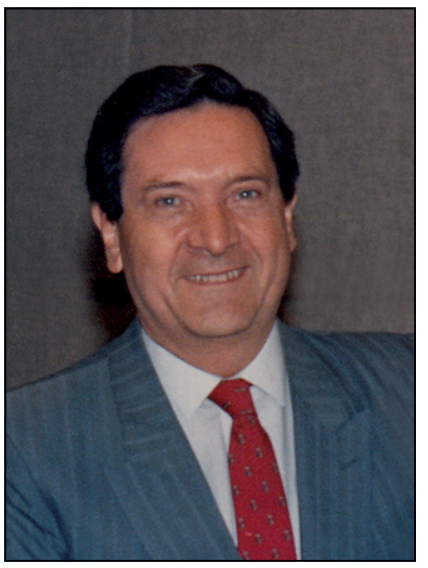

Me ha correspondido en mi calidad de Presidente de la SER hacer un homenaje póstumo al Dr. Edgardo Carrasco Calderón. Se mezclan sentimientos encontrados: es un honor hacerlo, pero jamás hubiera deseado hacerlo. Es un inmenso dolor despedir a un socio ejemplar, a un gran maestro y por sobre todo una persona íntegra.

El Dr. Carrasco Calderón llegó a estudiar Medicina a Santiago desde las nortinas tierras de Iquique y obtiene su título de Médico-Cirujano el año 1953, año especialmente importante para él, ya que en este mismo año se casa con la Sra. Angela Casals, su compañera de toda la vida y persona muy importante, tanto desde el punto de vista familiar y en su desarrollo profesional.

El año 1954 inicia su exitosa y brillante carrera profesional en el Servicio y Cátedra de Medicina del Profesor Rodolfo Armas Cruz, en el Hospital San Juan de Dios. Podríamos decir que el destino o la atracción de personas brillantes, es que conoce al Dr. Victorino Farga, con quién hace un gran equipo de trabajo y en los dos años siguientes forman el Departamento de Enfermedades Respiratorias del Hospital San Juan de Dios. Su vocación ya estaba definida.

Demuestra de inmediato su inquietud intelectual que mostró siempre. Realiza estudios de Postgrado en las Unidades de Alergia y Enfermedades Respiratorias del Massachussets General Hospital, en la Universidad de Harvard en Boston, entre los años 1958 y 1960. Como fue una característica de su vida, este beneficio personal, lo da a conocer y generosamente lo comparte al regresar a Chile. Entrega sus conocimientos acerca de los procedimientos diagnósticos y nuevos tratamientos para las enfermedades respiratorias alérgicas, constituyéndose en un pionero en la adecuada y correcta integración de la Alergología e Inmunopatología en Chile y como se presentan en diferentes patologías.
Nuestro país se beneficia además, ya que se compromete y participa activamente en la creación del Centro de Enfermedades Broncopulmonares del Hospital San Juan de Dios (CEBP). En éste es destacable su contribución a la formación de la primera central de tratamiento ambulatorio para los pacientes con Tuberculosis, hecho inédito en esa época y en lograr la incorporación de la Tisiología como una Subespecialidad de la Medicina Interna.

Paralelamente a estas actividades, le coresponde participar en el famoso simposio CIBA (1966) que define por primera vez Asma, Bronquitis Crónica y Enfisema pulmonar. Ha sido destacado su aporte también en la guía de Asma (GINA), cuyos contenidos modificaron la forma de entender y tratar el Asma en el mundo.

Otro de los aspectos relevantes de la vida del Dr. Carrasco, fue su nombramiento, en 1971, como Profesor Titular de Medicina de la Universidad de Chile. Tres años después, en 1974, emprende el proyecto INERyCT, Instituto Nacional de Enfermedades Respiratorias y Cirugía Torácica, actual Instituto Nacional del Tórax. En él se desempeñó como su director hasta 1989, logrando hechos pioneros en la Medicina, como fue la integración de las patologías respiratorias como Tuberculosis, Alergia, Cirugía torácica y cardiotorácica y otras patologías que requieren cuidados intensivos. Complementa su labor como médico en este recinto al incorporar la docencia en su quehacer diario.

Muchos de los aquí presentes, pueden dar fe de la calidad docente del Dr. Carrasco, y se reconocen como sus discípulos. Formó además

\footnotetext{
*Discurso pronunciado en la inauguración de las 34 ${ }^{\text {as }}$ Jornadas de Otoño de la Sociedad Chilena de Enfermedades Respiratorias (SER), Olmué, 27 de marzo de 2015.
} 
numerosas generaciones de especialistas nacionales y extranjeros. Debo destacar, además, en su capacidad de gestión la realización de numerosos cursos y de gran calidad, tales como el "Curso de Avances en Asma Bronquial”, del cual fue su Director entre 1980 y 2010, patrocinado por el Instituto Nacional de Enfermedades Respiratorias, el Ministerio de Salud y la Escuela de Postgrado de la Facultad de Medicina de la Universidad de Chile. A éste se añadió, entre 1995 y 2010, otro curso de gran impacto, el conocido curso "Avances en EPOC".

Fue un decidido impulsor y apoyó permanentemente la revista "Enfermedades Respiratorias y Cirugía Torácica", que como ustedes recuerdan nació en 1985 y desde 1990 pasa a ser el órgano oficial de la SER, denominándose Revista Chilena de Enfermedades Respiratorias. Continuó ligado permanentemente a ella, en su calidad de Editor Asociado.

En ese mismo período, entre el año 1990 y 1991, fue Presidente de la Sociedad Chilena de Enfermedades Respiratorias, siendo además Presidente de la Sociedad Chilena de Alergia e Inmunología y de la Comisión de Enfermedades Respiratorias de la Comisión Nacional Autónoma de Certificaciones Médicas (CONACEM).

Siempre se dio tiempo además para participar en numerosas agrupaciones científicas y perteneció y fue un socio activo en American Academy of Asthma and Immunology, American College of Chest Physicians, British Society of Asthma and Immunology y Asociación Latinoamericana de Tórax (ALAT).

El Dr. Edgardo Carrasco Calderón fue nombrado Maestro de la Especialidad el año 2009, durante el desarrollo del $42^{\circ}$ Congreso Chileno de Enfermedades Respiratorias, la más alta distinción que la Sociedad otorga a sus socios. En esa oportunidad, le correspondió rendir el homenaje a la Dra. Liliana Vicherat, quien resume en una de sus frases la opinión consensuada de dife- rentes colegas. Lo define como una persona con "incansable capacidad de trabajo, ser creativo e innovador, con visión de futuro, perseverante, fanático por el estudio, perfeccionista, generoso con sus conocimientos, docente de corazón y todo eso aplicado al progreso de nuestra especialidad". Me permito agregar además que era amigo de sus amigos y una persona recta e íntegra. Alguien en quien se podía confiar y esperar una palabra cariñosa de estímulo en sus actividades o de una crítica con altura de miras.

La ciencia médica tiene una evidencia permanentemente en el legado que le deja en sus más de 100 publicaciones en revistas nacionales y extranjeras. En ellas podemos encontrar valiosos contenidos en temas tales como Quimioterapia de la tuberculosis pulmonar, Enfermedades bronquiales obstructivas, Asma y refujo gastroesofágico, Aspergilosis broncopulmonar alérgica y Guías para el manejo del Asma bronquial.

Estimadas y estimados colegas, he tratado de ser lo más fiel posible en el recuerdo del Dr. Carrasco. No es fácil en algunos minutos resumir la vida de un hombre tan productivo como él y cuando los sentimientos están presentes en su recuerdo.

El fue un médico de ciencia, entregando contenidos y nuevos conocimientos a su actividad profesional. Pero siempre además, recordando que la individualidad y variabilidad del ser humano obliga a aplicar estos conocimientos en cada persona y por lo tanto siendo la Medicina una ciencia, la forma de aplicar cada uno de estos conocimientos a un determinado paciente en particular, transforma la Medicina en un Arte.

En esto el Dr. Carrasco, fue un maestro.

Dr. Edgardo Carrasco Calderón, gracias por haber estado entre nosotros.

Dr. Mario Calvo G. Presidente, Sociedad Chilena de Enfermedades Respiratorias 